\title{
PREVALENCE AND DETERMINANTS OF UNDIAGNOSED HYPERTENSION AMONG SLUM DWELLERS: A COMMUNITY-BASED CROSS-SECTIONAL SURVEY
}

\author{
RAJSINH MOHITE ${ }^{1}$, VAISHALI MOHITE ${ }^{2 *}$ \\ ${ }^{1}$ Department of Community Medicine, Krishna Institute of Medical Sciences, Karad, Maharashtra, India. ${ }^{2}$ Dean, Krishna Institute of \\ Nursing Sciences, Karad, Maharashtra, India. Email: rajsinhmohite124@gmail.com
}

Received: 13 August 2019, Revised and Accepted: 03 September 2019

\section{ABSTRACT}

Objectives: The objectives of the study were to determine the prevalence and determinants of undiagnosed hypertension (HTN) in slum population and to its strength of association.

Methods: A community-based cross-sectional survey was conducted at Karad urban slum area of district Satara, India in the year 2018. The study was conducted among randomly selected 460 adults were in age ranges from 18 to 60 years. A standard World Health Organization-stepwise approach questionnaire includes demographic data, behavioral information, and clinical examination; anthropometric data were employed to elicit the data from the eligible study participants by interview and examination method. Inferential statistics were worked out to determine the significant statistical association among variables under study.

Results: The prevalence of HTN among adult slum dweller was $23.04 \%$ of which prevalence of undiagnosed HTN was $16.03 \%$. Significantly higher proportions of undiagnosed hypertensive were seen in males $22 \%$ and females $15.5 \%$ as well as also in all age groups, and it was seen twice in males as compared to females. The risk factor prevalence of current exposure to tobacco was $88.47 \%$ of which higher proportion, $90.7 \%$ was seen in females. Alcohol exposure was seen in 25\% participants of which higher proportion, $38.5 \%$ seen in males and maximum exposure was seen in $46.7 \%$ males and $38.8 \%$ females and were from the young age group 18-30 years. Daily fruits and pure vegetarian diet consumption was observed in $3.2 \%$ and $19.3 \%$ slum dwellers, respectively. The prevalence of physical exercise was $17.1 \%$ of which significantly higher proportion, $22.0 \%$ was seen males and was of 1.8 times more than females. Overweight/obesity (body mass index $>25 \mathrm{~kg} / \mathrm{m}^{2}$ ) reported was $25.4 \%$ of which higher proportion, $26.9 \%$ was seen in females and they were maximum, $31.0 \%$ and $32.8 \%$ in males and females and from the age group of $40-50$ years.

Conclusion: Study revealed the prevalence of undiagnosed HTN at alarming state among the people residing in slum habitations. Similarly, risk factors such as tobacco, alcohol, physical inactivity, obesity, and dietary patterns were strongly existence among participants.

Keywords: Prevalence, Undiagnosed hypertension, Risk factors, Slum dwellers, Association.

(c) 2019 The Authors. Published by Innovare Academic Sciences Pvt Ltd. This is an open access article under the CC BY license (http://creativecommons. org/licenses/by/4. 0/) DOI: http://dx.doi.org/10.22159/ajpcr.2019.v12i10.35334

\section{INTRODUCTION}

Hypertension (HTN) is a global health problem. In India, it is estimated to range from 4 to $8 \%$ and the trend is increasing due to an epidemiological transition. A recent World Health Organization (WHO) report indicates that nearly 1 billion adults globally had HTN in 2000 and this is predicted to increase to 1.56 billion by 2025 [1-3]. The WHO has further projected that by 2030 , stroke alone will emerge as the main cause of death (36\%) in India and HTN is considered as the main risk factor.

HTN alone accounts for $30-50 \%$ of the stroke cases in India. Government of India had supported in the prevention and control of non-communicable diseases (NCDs) through several vertical programs; however, there was considerable upsurge to prevent and control NCDs [4]. Vast knowledge now exists about the risk factors and NCDs and experience in the prevention and control even in low- and middle-income countries. A current need is to addresses the community-based interventions require country-specific data on risk factors so that priorities can be appropriately set and targeted interventions developed and monitored. For data collection process to most effectively inform this process, the data must be collected, analyzed, and used regularly and systematically.

The study designed to assess the growing need of the slum community according to the trend of HTN and top priority of modifiable risk factors based on a standard WHO questionnaire which was not yet studied enormously in India [5]. The data can be generalized and compare for national as well as international level. The information can, in turn, be used to plan for disease prevention through population-level risk factor reduction in the slum community.

\section{METHODS}

A community-based, cross-sectional study was conducted as a house to house survey among adult population residing at Karad urban slum area of Western Maharashtra, India. The study was conducted for 6 months in the year 2018. The total of 460 eligible study subjects was selected from the study area with age ranges of 18-60 years as per following sample size formula;

$$
\begin{gathered}
\mathrm{N}=4 \mathrm{pq} / \mathrm{L}^{2} \times \mathrm{DE}+\mathrm{NR} \\
=\frac{4 \times 15.15 \times 84.85 \times 2+10 \%}{5 \times 5}
\end{gathered}
$$

$=452$, But to roundup, we enrolled 460 as sample size to conduct the present study.

( $\mathrm{N}$ = sample size, $\mathrm{p}=$ prevalence of hypertension, $\mathrm{q}=1-\mathrm{p}, \mathrm{L}=$ allowable error, $\mathrm{DE}=$ design effect, and NR = nonresponse).

To estimate the sample size, we considered that the prevalence of HTN among Maharashtra slum population was $15.15 \%$ reported by Bendhari et al. [6]. 
Inclusion criteria

Permanent resident of the study area, age ranges from 18 to 60 years as per the WHO-step approach criteria, available at the time of the survey and willing to participate were include in the study.

\section{Exclusion criteria}

Pregnant mothers were excluded from the study.

The study tool used to collect data was a standard WHO-stepwise approach questionnaire designed for surveillance for NCDs. The approach has three levels of the questionnaire that includes demographic data, behavioral information, and clinical examination; anthropometric data and blood pressure. The principal investigator visited the houses as per the list provided by Urban Health Training Centre during morning hours along with the medical social worker and interviewed and examined the eligible study participants. At the time of the study, there were 365 households (huts) in the study area. A list of eligible study subjects from each household was prepared by the medical social worker and then by employing random sample selection technique, the total of 460 participants was selected, interviewed, and examined at the household level. The data so generated were coded and decoded, presented in tabular form and finally analyzed using SPSS, version 20 software. Person Chi-squared test was used to test for statistical significance between variables under study, and if $p<0.05$, the difference observed was considered statistically significant at a $95 \%$ confidence interval. The odd's ratio was worked out to estimate the strength of association between study variables at a $95 \%$ confidence interval. An approval of Institutional Human Research Ethics Committee Clearance was obtained before the commencement of research study and informed written consent of enrolled participants was obtained before the data collection.

\section{RESULTS}

In the present study, the baseline data comprised a total of 460 participants with age ranged 18-60 years. Max. participants, 40.65\% were young adults, $56.5 \%$ females, $46.08 \%$ illiterates, and $90.86 \%$ were belonged to low socio-economic status Class-V according to modified BG Prasad classification (AICPI 2018), respectively (Table 1).

Fig. 1 shows that the point prevalence of HTN (PP-HTN) among adult slum dwellers was $23.04 \%$. The prevalence of undiagnosed HTN (UKHTN) recorded was $16.03 \%$, whereas the prevalence of known HTN was $6.73 \%$, respectively.

Table 2 depicts that the PP-HTN was significantly higher, 30.5\% in males as compared to females, $17.3 \%$ as indicated by $\mathrm{p}<0.05$. The proportions of the prevalence of undiagnosed HTN were maximum, $22 \%$ and $15.5 \%$ in both males and females and in all age groups too. The strength of the association of HTN was 2 times more in males as compared to females as indicated by odd's ratio and confidence interval. The prevalence of HTN was maximum, $42.6 \%$ and $48.8 \%$ in the age group of 40-50 years in both male and females. As age increases from 18 to 60 years, the prevalence of HTN (PP, the prevalence of undiagnosed and diagnosed HTN) in both male and females, also increases and there was a significant association between age and HTN as denoted by $\mathrm{p}<0.05$.

Among the 460 participants, maximum, $88.47 \%$ were exposed to tobacco either in any form or of which higher proportion, $90.7 \%$ were seen in the female population. In both male and female participants, the maximum proportion of exposure to tobacco, $41.5 \%$ and $40.6 \%$ was seen in the age group of 18-30 years and as age increases, exposure to tobacco was seen on decreasing; however, maximum proportions were seen in each age group, respectively. The alcohol exposure was seen in $25 \%$ of the study subjects of which higher proportion, $38.5 \%$ was seen in males and this gender difference was statistically significant $(p<0.05)$. The consumption of alcohol was seen maximum, $46.7 \%$ in males and $38.8 \%$ in females and they were from the young age group of 18-30 years (Table 3 ).
Table 1: Baseline characteristics of study participants $(n=460)$

\begin{tabular}{ll}
\hline Socio-demographic variables & Frequency (\%) \\
\hline Age (years) & \\
$18-30$ & $187(40.65)$ \\
$30-40$ & $105(22.82)$ \\
$40-50$ & $91(19.78)$ \\
$50-60$ & $77(16.73)$ \\
Gender & \\
Male & $200(43.5)$ \\
Female & $260(56.5)$ \\
Education & \\
Illiterate & $212(46.08)$ \\
Primary & $121(26.30)$ \\
Secondary & $72(15.62)$ \\
Higher secondary & $54(11.73)$ \\
Graduates & $1(00.21)$ \\
Occupation & \\
Daily wage labor & $358(77.82)$ \\
Housewife & $65(14.13)$ \\
Salaried & $31(6.73)$ \\
Businessman & $6(1.30)$ \\
Socio-economic status & \\
Class I & $0(00.00)$ \\
Class II & $0(00.00)$ \\
Class III & $14(3.04)$ \\
Class IV & $28(6.08)$ \\
Class V & $418(90.86)$ \\
\hline
\end{tabular}

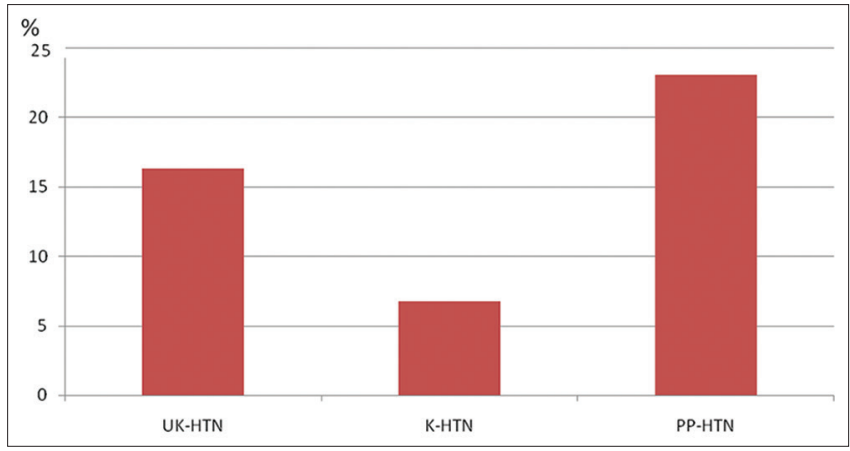

Fig. 1: Prevalence of hypertension

According to Table 4, daily fruits consumption was observed among $3.2 \%$ slum dwellers of which male and female proportion was $3.5 \%$ and $3.0 \%$, respectively. The percentage of the population with pure vegetarian consumption was seen in $19.3 \%$ of which proportion of male and female was $16 \%$ and $21.9 \%$, respectively. The participants consuming fruits, max. $42.8 \%$ from males and 37.55 from females were from the age group of 30-40 to 40-50 years, respectively. Maximum, $34.3 \%$ males and $38.5 \%$ females consuming only vegetarian diet were from the age group of 18 to 30 years. The proportions of exposure to fruits were very low in each age group from both male and female participants; however, max. $28.8 \%$ males and $26.0 \%$ females were vegetarian and confined to age group of 50-60 years.

Table 5 shows that $17.1 \%$ study subjects were following daily physical exercise either of any type apart from their routine work and among them, the proportion of males were significantly higher, $22.0 \%(\mathrm{p}<0.05)$ than females. The males were doing 1.8 times more physical exercise than females, as indicated by odd's ration and confidence interval. The prevalence of overweight and obesity (body mass index $>25 \mathrm{~kg} / \mathrm{m}^{2}$ ) observed was $25.4 \%$ among adult slum dwellers of which max. $26.9 \%$ proportion was seen in females. The prevalence of overweight and obesity was maximum, $31.0 \%$ in males and $32.8 \%$ in females were from the age group of $40-50$ years. As age increases, the risk of obesity and overweight also increases as indicated by $\mathrm{p}<0.05$. 
Table 2: Age and gender-wise presentation of hypertension

\begin{tabular}{lllllllll}
\hline Age (years) & Male & K-HTN (\%) & UK-HTN (\%) & PP-HTN (\%) & Female & K-HTN (\%) & UK-HTN (\%) & PP-HTN (\%) \\
\hline $18-30$ & 85 & $0(00.0 \%)[00.0 \%]$ & $3(06.8 \%)[100.0 \%]$ & $3(4.9 \%)$ & 102 & $0(00.0 \%)[00.0 \%]$ & $1(03.2 \%)[100.0 \%]$ & $1(02.2 \%)$ \\
$30-40$ & 45 & $0(00.0 \%)[00.0 \%]$ & $10(22.7 \%)[100.0 \%]$ & $10(16.3 \%)$ & 60 & $1(07.1 \%)[25.0 \%]$ & $3(09.6 \%)[75.0 \%]$ & $4(08.8 \%)$ \\
$40-50$ & 39 & $9(52.9 \%)[34.6 \%]$ & $17(38.6 \%)[65.3 \%]$ & $26(42.6 \%)$ & 52 & $7(50.0 \%)[31.8 \%]$ & $15(48.3 \%)[68.1 \%]$ & $22(48.8 \%)$ \\
$50-60$ & 31 & $8(47.0 \%)[36.3 \%]$ & $14(31.8 \%)[63.6 \%]$ & $22(36.0 \%)$ & 46 & $6(42.8 \%)[33.3 \%]$ & $12(38.7 \%)[66.6]$ & $18(40.0 \%)$ \\
Total & 200 & $17(8.5 \%)$ & $44(22.0 \%)$ & $61(30.5 \%)$ & 260 & $14(5.3 \%)$ & $31(15.5 \%)$ & $45(17.3 \%)$ \\
\hline
\end{tabular}

Statistical analysis: Age: $\chi^{2}=133.2, \mathrm{p}=0.001$, gender: $\chi^{2}=10.36, \mathrm{p}=0.001, \mathrm{OR}=2.0, \mathrm{CI}=1.3-3.2$. OR: Odds ratio, CI: Confidence interval

Table 3: Current exposure of tobacco and alcohol among community population

\begin{tabular}{lllll}
\hline Male & Tobacco exposure & Alcohol exposure & Female & Tobacco exposure \\
\hline 85 & $71(41.5 \%)[83.5 \%]$ & $36(46.7 \%)[42.3 \%]$ & 102 & $96(40.6 \%)[94.1 \%]$ \\
45 & $39(22.8 \%)[86.6 \%]$ & $17(22.0 \%)[37.7 \%]$ & 60 & $57(24.1 \%)[95.0 \%]$ \\
39 & $35(20.4 \%)[89.7 \%]$ & $13(16.8 \%)[33.3 \%]$ & 52 & $43(18.2 \%)[82.6 \%]$ \\
31 & $26(15.2 \%)[83.8 \%]$ & $11(14.2 \%)[35.4 \%]$ & 46 & $9(23.6 \%)[15.0 \%]$ \\
200 & $171(85.5 \%)$ & $77(38.5 \%)$ & 260 & $9(23.6 \%)[17.3 \%]$ \\
\hline
\end{tabular}

Statistical analysis: Tobacco exposure (gender): $\chi^{2}=2.58, \mathrm{p}=0.10, \mathrm{OR}=0.5, \mathrm{CI}=0.3-1.0$, alcohol exposure (gender): $\chi^{2}=33.1, \mathrm{p}=0.001, \mathrm{OR}=3.6, \mathrm{CI}=2.3-5.7$, tobacco exposure (age): $\chi^{2}=3.1, \mathrm{p}=0.36$, alcohol exposure (age): $\chi^{2}=0.6, \mathrm{P}=0.8$

Table 4: Prevalence of current use of fruits and vegetables by community

\begin{tabular}{llllll}
\hline Male & Fruits/day & Pure veg. & Female & Fruits/day & Pure veg. \\
\hline 85 & $2(28.5 \%)[2.3 \%]$ & $11(34.3 \%)[12.9 \%]$ & 102 & $1(12.5 \%)[0.9 \%]$ & $22(38.5 \%)[21.5 \%]$ \\
45 & $3(42.8 \%)[6.6 \%]$ & $6(18.7 \%)[13.3 \%]$ & 60 & $2(25.0 \%)[3.3 \%]$ & $13(22.8 \%)[21.6 \%]$ \\
39 & $2(28.5 \%)[5.1 \%]$ & $7(21.8 \%][17.9 \%]$ & 52 & $3(37.5 \%)[5.7 \%]$ & $10(17.5 \%)[19.2 \%]$ \\
31 & $0(0.0 \%)[0.0 \%]$ & $8(25.0 \%][28.8 \%]$ & 46 & $2(25.0 \%)[4.3 \%]$ & $12(21.0 \%)[26.0 \%]$ \\
200 & $7(3.5 \%)$ & $32(16.0 \%)$ & 260 & $8(3.0 \%)$ & $57(21.9 \%)$ \\
\hline
\end{tabular}

Statistical analysis: Fruits (gender): $\chi^{2}=0.06, \mathrm{p}=0.8, \mathrm{OR}=1.1, \mathrm{CI}=0.4-3.2$, pure veg. (gender) $\chi^{2}=2.1, \mathrm{p}=0.1, \mathrm{OR}=0.6, \mathrm{CI}=0.4-1.0$, fruits (age): $\chi^{2}=6.4, \mathrm{p}=0.08, \mathrm{pure}$ veg. (age): $\chi^{2}=2.6, \mathrm{p}=0.4$

Table 5: Prevalence of physical activity among community

\begin{tabular}{llllll}
\hline Male & Physical exercise (daily) & Overweight and obesity & Female & Physical exercise (daily) & Overweight and obesity \\
\hline 85 & $18(40.9 \%)[21.1 \%]$ & $11(23.4 \%)[12.9 \%]$ & 102 & $6(17.1 \%)[5.8 \%]$ & $11(15.7 \%)[10.7 \%]$ \\
45 & $8(18.1 \%)[17.7 \%]$ & $10(21.2 \%)[22.2 \%]$ & 60 & $12(34.2 \%)[20.0 \%]$ & $17(24.2 \%)[28.3 \%]$ \\
39 & $10(22.7 \%)[25.6 \%]$ & $15(31.0 \%)[38.4 \%]$ & 52 & $7(20.0 \%)[13.4 \%]$ & $23(32.8 \%)[44.2 \%]$ \\
31 & $8(18.1 \%)[25.8 \%]$ & $11(23.4 \%)[35.4 \%]$ & 46 & $10(28.5)[21.7 \%]$ & $19(27.1 \%)[41.3 \%]$ \\
200 & $44(22.0 \%)$ & $47(23.5 \%)$ & 260 & $35(13.4 \%)$ & $70(26.9 \%)$ \\
\hline
\end{tabular}

Statistical analysis: Physical exercise (gender): $\chi^{2}=5.2, \mathrm{p}=0.02, \mathrm{OR}=1.8, \mathrm{CI}=1.1-2.9$, overweight and obesity (gender): $\chi^{2}=0.4, \mathrm{p}=0.5, \mathrm{OR}=0.8, \mathrm{CI}=0.5-1.2, \mathrm{physical}$ exercise (age): $\chi^{2}=4.2, p=0.2$, overweight and obesity (age): $\chi^{2}=38.6, p=0.001$

\section{DISCUSSION}

The present study revealed that PP-HTN was $23.4 \%$ among slum adolescents of which proportion of undiagnosed cases was $16.03 \%$, and data depict that huge mass of patients with undiagnosed hypertension still exists in the community and could be one of the important causes for high mortality and disability in India. A study conducted in China [7] accounted for undiagnosed hypertension was 12.3\%; however, population-based study conducted in Kerala [8] and rural Sudan [9] shows that incidence of HTN was $23.6 \%$ and $38.2 \%$, respectively, and results were much higher than present study and reason could be acculturation, emerging trend of western lifestyle and increased purchasing power as compared to population residing in slum area.

The study shows that age is significantly associated with the prevalence of UK-HTN. Similar findings have been also reported by Bushara et al. in a study conducted at Sudan [9] and Ahmed et al. [10] among Bangladesh slum community. Age is a known non-modifiable risk factor for HTN represented in every community across the globe. The present study identified a high prevalence of undiagnosed HTN among males. A similar finding has been also reported by Supriya and Zaozianlungliu from West Delhi [11]; however, a controversial statement passed by Ahmed et al. [10] and difference could be due to low physical activities by Bangladesh females. Similarly, among the slum population, poverty and stress might be responsible for the problem statement in the present study. The prevalence of HTN was seen twice in males as compared to females, and similar findings have been also recorded in a study conducted among the Chinese population.

The prevalence of current exposure to any form of tobacco product was $88.47 \%$ of which significantly higher proportion, $90.7 \%$ was seen in females and was due to exposure to Mishri as a smokeless form of tobacco. Exposure rate of smoking was $66.7 \%$ reported among slum dwellers of Mumbai [12], whereas chewing tobacco was 55.5\%, respectively. Traditional belief and culture, poor awareness about the hazards of tobacco, easily available and affordable tobacco products could be responsible for high exposure rate among study population as compare people residing in slum areas of Myanmar (22.0\%) [13], and Chennai (20.2\%) [14], and Patna (12.54\%) [15], respectively. A study conducted in Myanmar [13] revealed a higher rate of, 51.4\% exposure to a smokeless form of tobacco in males. It is universally recorded that tobacco consumption is highly confined to people residing in developing and under-developed countries as they are coming from a low-income group with illiteracy and poor knowledge about tobacco and health.

Alcohol exposure was seen in 25\% participants of which higher proportion, $38.5 \%$ seen in males and maximum exposure was seen in $46.7 \%$ males and $38.8 \%$ females and were from the young age group of 18-30 years. A study conducted in the slum area of Nepal [16] and 
Mumbai [12] reported that the prevalence of alcohol was 38.5\% and $31.2 \%$ with a higher proportion in males in 35-44 years of age group. A study conducted in Kerala [8] also reported high alcohol exposure rate, $45.4 \%$ among young adult study participants. The differences in results could be due to the geographical distribution of study sites and subjects. Income, occupation, and metro-culture may result in high exposure among study participants as compared to the present study population.

Daily fruits and pure vegetarian diet consumption was observed in $3.2 \%$ and $19.3 \%$ slum dwellers, respectively. More than five servings of fruit and vegetables are recommended for healthy living, but more than $95 \%$ consume fewer fruits and more than $80 \%$ vegetables than recommended five servings daily. Similar findings have been also reported in a study conducted at Nepal [16] slum area. However, Chennai [14] and Myanmar [13] urban slum population had better fruit and vegetable consumption and difference might be due to poverty, poor dietary health knowledge, and preference to local monotonous food habits in the present study population.

The prevalence of physical exercise/activity was $17.1 \%$ among the study population with a significantly higher proportion, $22.2 \%$ in males. A similar finding has been also reported in the study conducted among Sinamangal [16] slum population. In fact, the women are more inactive than males also reported by the studies conducted at Patna [15] and Kerala [8] slum settlements. Apart from routine physical work which was carried out for bread and butter furthermore, physical activity/ exercise is required for maintenance of cardio-respiratory as well as musculoskeletal strengthening as body physics.

The study depicts that the prevalence of overweight/obesity was $25.4 \%$ of which high proportion, $26.9 \%$ was seen in females. As age increases, the risk of overweight/obesity also increases as indicated by $\mathrm{p}<0.05$. Similar results have also been reported by Bushara et al. from Sudan [9], Ahmed et al. [10] from Bangladesh, and Oli et al. from Nepal [16] community, respectively. The prevalence of overweight/obesity was higher in women than men observed in urban Myanmar [13], Kerala [8], and even in the Mumbai [12] slum habitats and results were similar to present study. Obesity is also universally accepted risk factor for HTN worldwide and in this study may due to hormonal changes, low level of physical exercise, poor awareness, and faulty dietary habits responsible for high prevalence of overweight/obesity among women population.

\section{CONCLUSION}

The study revealed that the prevalence of HTN is at alarming state among the people residing in slum habitations. Poverty, illiteracy, ignorance, and lack of health-care services are responsible for negative attitude toward personal health which resulted in high burden of undiagnosed HTN among community members. Extensive information, education and communication activities need to be incorporated along with different stakeholders to change the behavior of community regarding risk factors of HTN to combat the global problem statement and place the community toward positive health.

\section{Limitations}

The results obtained from the present study are confined to only adult population and confined to slum habitants.

\section{AUTHORS' CONTRIBUTIONS}

The study concept, study tool preparation, training, and data collection supervision was carried out by Dr. Rajsinh Mohite. Data entry, analysis, and manuscript preparation, editing and plagiarism check were done by Dr. Mohite Vaishali.

\section{CONFLICTS OF INTEREST}

The authors declared that there have no conflicts of interests.

\section{REFERENCES}

1. Suryakanta AH. Text Book of Community Medicine with Recent Advances. $3^{\text {rd }}$ ed. India: Jaypee Publishers; 2014

2. Park K. Text Book of Community Medicine. $23^{\text {rd }}$ ed. India: Banarasidas Bhanot Publishers; 2015.

3. WHO-STEP Wise Approach to Non Communicable Disease Risk Factors Surveillance (STEPS). Available from: http://www.who.int. [Last accessed on 2015 Sep 07].

4. Murray CJ, Lopez AD. Alternative projections of mortality and disability by cause 1990-2020: Global burden of disease study. Lancet 1997;349:1498-504

5. Gupta R, Joshi P, Mohan V, Reddy KS, Yusuf S. Epidemiology and causation of coronary heart disease and stroke in India. Heart 2008;94:16-26.

6. Bendhari M, Korade R, Haralkar S. Study of prevalence and risk factors of hypertension in adults in an urban slum area of Western Maharashtra, India. Int J Community Med Public Health 2016;3:2812-16.

7. Zhang H, Deng M, Xu H, Wang H, Song F, Bao C, et al. Pre-and undiagnosed-hypertension in urban Chinese adults: A population-based cross-sectional study. J Hum Hypertens 2017;31:263-9.

8. Sathish T, Kannan S, Sarma PS, Razum O, Thankappan KR. Incidence of hypertension and its risk factors in rural Kerala, India: A communitybased cohort study. Public Health 2012;126:25-32.

9. Bushara SO, Noor SK, Elmadhoun WM, Sulaiman AA, Ahmed MH. Undiagnosed hypertension in a rural community in Sudan and association with some features of the metabolic syndrome: How serious is the situation? Ren Fail 2015;37:1022-6.

10. Ahmed S, Tariqujjaman M, Rahman MA, Hasan MZ, Hasan MM. Inequalities in the prevalence of undiagnosed hypertension among bangladeshi adults: Evidence from a nationwide survey. Int J Equity Health 2019;18:33.

11. Supriya D, Zaozianlungliu G. Prevalence of hypertension among adult population in slum of West Delhi. Asian J Pharm Clin Res 2017;10:350.

12. Waingankar P, Pandit D. A cross sectional study of coronary heart disease in urban slum population of Mumbai. Int J Med Clin Res 2012;3:180-9.

13. World Health Organization. Non-Communicable Disease Risk Factor Survey Myanmar 2009. New Delhi: World Health Organization; 2011.

14. Nath A, Garg S, Deb S, Ray A, Kaur R. A study of the profile of behavioral risk factors of non communicable diseases in an urban setting using the WHO steps 1 approach. Ann Trop Med Public Health 2009;2:15-9

15. Singh R, Mukherjee M, Kumar R, Pal R. Study of risk factors of coronary heart disease in urban slums of Patna. Nepal $\mathrm{J}$ Epidemiol 2012;2:205-12

16. Oli N, Vaidya A, Thapa G. Behavioural risk factors of noncommunicable diseases among nepalese urban poor: A descriptive study from a slum area of Kathmandu. Epidemiol Res Int 2013;2013:1-13. 